\title{
Thinking critically about the occurrence of widespread participation in poor nursing care
}

\author{
Marc Roberts, Robin Ion
}

This is the peer reviewed version of the following article:

Roberts, M. and Ion, R. 2014. Thinking critically about the occurrence of widespread participation in poor nursing care. Journal of Advanced Nurisng. 71(4): pp.768-776. Available from DOI: 10.1111/jan.12586

which has been published in final form at http://doi.wiley.com/10.1111/jan.12586. This article may be used for non-commercial purposes in accordance With Wiley Terms and Conditions for self-archiving. 


\title{
Thinking critically about the occurrence of widespread participation in poor nursing care
}

\author{
Authors \\ Marc Roberts, Abertay University, Division of Nursing and Counselling \\ Robin Ion, Abertay University, Division of Nursing and Counselling
}

\begin{abstract}
Aim. A discussion of the manner in which Hannah Arendt's work can be productively re-contextualised to provide a critical analysis of the occurrence of widespread participation in poor nursing care, and what the implications of this are for the providers of nursing education.
\end{abstract}

Background. While the recent participation of nurses in health care failings, such as that detailed in the Francis report, has been universally condemned, there has been an absence of critical analyses in the literature that attempt to understand the occurrence of such widespread participation in poor nursing care. This is a significant omission in so far as such analyses will form an integral part of the strategy to limit the occurrence of such widespread participation of nurses in future health care failings.

Design. Discussion paper. 
Data Sources. Hannah Arendt's Eichmann in Jerusalem: A Report on the Banality of Evil and Thinking and Moral Considerations: A Lecture. In addition, a literature search was conducted and articles published in English relating to the terms care, compassion, ethics, judgement and thinking between 2004-2014 were included.

Implications for Nursing. It is anticipated that this discussion will stimulate further critical debate of the role of Arendt's work for an understanding of the occurrence of poor nursing care, as well as encouraging additional detailed analyses of the widespread participation of nurses in health care failings more generally.

Conclusion. This article provides a challenging analysis of the widespread participation of nurses in poor care and discusses the opportunities confronting the providers of nursing education in limiting future health care failings.

Keywords. Arendt, caring, compassion, critical analysis, ethics, nursing, nursing education, politics, philosophy, Socrates 


\section{Summary statement}

\section{Why is this research or review needed?}

- Understanding the occurrence of widespread participation in poor nursing care should be a key priority for nursing practice, education, research and policy.

- There is a lack of detailed, critical analyses in the literature that seeks to account for the widespread participation of nurses in poor nursing care.

- Detailed and informed analysis of why poor nursing care occurs in modern health care organisations will be integral to considering how best to limit the occurrence of future health care failings.

\section{What are the key findings?}

- The widespread occurrence of failings in nursing care cannot coherently be understood by invoking notions of individual wickedness, pathology or deficiency but should rather be understood as a consequence of what Hannah Arendt refers to as an 'authentic inability to think' or 'thoughtlessness'.

- Thoughtlessness can be understood as an habituation to the instrumental, rule governed rationality that has become increasingly prevalent in modern health care organisations and that has come to govern the everyday clinical activities of nurses.

- The facilitation of a Socratic disposition to question in nursing students has the potential to disrupt the habituated thoughtlessness that can be associated with instrumental rationality, and which may thereby limit the widespread participation of nurses in future health care failings. 
How should the findings be used to influence policy, practice, research and education?

- The findings should be used across policy, practice, research and education to challenge established accounts of the occurrence of widespread participation in poor nursing care.

- The findings should be used to consider the opportunities and challenges confronting those nurse educationalists who would seek to limit the widespread participation of nurses in future health care failings.

- The findings should be used to stimulate further critical debate about the significance of Arendt's work for an understanding of the widespread participation of nurses in poor care, and to stimulate further critical analyses of the participation of nurses in poor care more generally. 


\section{Introduction}

The British health care system has been subject to intense critical scrutiny over recent years which has, in part, occurred as a result of a series of reports that have questioned the quality of care provision and the levels of compassion displayed by the professional groups providing that care (e.g. Health Service Ombudsman 2011, Patients' Association 2011, Francis 2013). Arguably the most significant and shocking of these has been the public inquiry into the events at the Mid Staffordshire NHS Foundation Trust in which Robert Francis QC identified 'appalling' levels of care provided by multiple health care agencies and professionals and, in particular, an absence of compassion that contributed to many 'needless deaths' and that was symptomatic of 'a culture of complacency' that prioritised 'corporate self-interests and cost control ahead of patients and safety' (Francis 2013, p. 10). However, while there has been widespread condemnation of the failings in care identified in the Francis report (e.g. Abbassi 2013, Darbyshire \& McKenna 2013, De Zulueta 2013, Holmes 2013), there has been an absence of detailed, critical analyses in the health care literature that attempt to account for how so many practitioners came to carry out, contribute to or be complicit in such morally reprehensible activity. In order to begin to respond to this apparent omission this discussion paper will draw upon the work of Hannah Arendt, the political journalist and public intellectual generally regarded as being one of the most influential thinkers of the late twentieth century (Swift 2009, Bowring 2011). In particular, it will argue that Arendt's work can be productively recontextualised to provide a detailed and challenging critical analysis of the occurrence of widespread failings in nursing care as well as enabling the providers of nursing education to begin to consider their role in limiting the occurrence of such widespread failings in the future. 


\section{Background}

The health care failings identified in the Francis report have been described as casting 'a large and dark shadow over the whole of the NHS' (Tingle 2014, p. 284) and, as an integral part of that organisation, have raised serious and wide ranging questions for nursing as a profession. Indeed, what has been so shocking to many has not only been the instances of poor nursing care, reprehensible in themselves, but the widespread occurrence of what has been referred to as 'inhumane care' (Kapur 2014, p. 16). In detailing such inhumane care, and the implications of its occurrence for nursing as a profession, Hayter (2013) has suggested that 'patients left to lie in excrement for lengthy periods, a widespread lack of recognition of patient dignity and privacy, failing to hydrate and feed patients adequately and a pervasive lack of compassion...this simply should not have happened - but it did - and has put the quality of nursing care and nursing education under the spotlight' (p. e1). However, while the widespread participation of nurses in such inhumane behaviour has met with universal condemnation, and while there has been critical discussion around the qualities of care and compassion and how their acquisition is to be facilitated (e.g. Dewar \& Nolan 2013, Horsburgh \& Ross 2013, Dewar et al. 2014), there has been apart from the inchoate suggestion that 'a psychological perspective' may be beneficial (e.g. Paley 2013, Garner 2014, Kapur 2014) - an absence of detailed analysis and discussion in the literature that attempts to understand the occurrence of such widespread failings in care. Indeed, in capturing the sense of astonishment at the nature and scope of the health care failings at Mid Staffordshire, and raising the critical questions that are, as yet, awaiting detailed analysis, De Zulueta (2013) asks: 'How did it come to this? How did the healthcare professionals so comprehensively lose their moral compass and eschew their fundamental duty to care for and protect 
their patients from harm and unnecessary suffering? How on earth can we make sense of it all?’ (p. 838).

In beginning to respond to such critical questions and address the apparent omission in the health care literature this discussion paper will provide a philosophical analysis of the occurrence of widespread participation in morally reprehensible activities and, in particular, will employ the work of Hannah Arendt to provide a detailed critical analysis of the occurrence of widespread participation in poor nursing care. While Arendt published widely on both politics and philosophy (e.g. Arendt 1981, 1985, 1990, 1998) she perhaps most memorably employed the trial of the prominent Nazi official Adolf Eichmann in order to provide a challenging and controversial account of how widespread and systemic 'moral catastrophes' could occur (Arendt 1971, 1992). In particular, it will be suggested that from an Arendtian perspective the widespread occurrence of failings in nursing care - such as that typified by the events at Mid Staffordshire - cannot coherently be understood by invoking notions of 'wickedness' or 'pathology' but should rather be understood as a consequence of what she refers to as an 'authentic inability to think' or 'thoughtlessness' (Arendt 1992, p. 288). Moreover, to the extent that modern health care organisations are increasingly characterised by instrumental rationality - a rationality that necessitates practitioners exercise their technical skills in accordance with institutional rules, policies and procedures - then Arendt's work suggests that practitioners within those organisations become progressively habituated to the thoughtless, unreflective adherence to organisational rules without considered reflection on their moral appropriateness. In considering the implications of this for nursing, this discussion paper will suggest that Arendt's work entails the need for what she refers to simply as 'thinking' and will argue that her characterisation of the 
ancient Greek philosopher Socrates can be understood as an exemplary instance of that thinking which can serve as a corrective to the thoughtlessness that can be associated with instrumental, rule-governed rationality. In particular, it will suggest that her critical employment of Socrates has important implications for the providers of nursing education and presents both opportunities and challenges for how to begin to consider developing that thinking which may limit the widespread participation of nurses in future health care failings.

\section{Data sources}

The two texts that were subject to a detailed reading and judged to be most pertinent to the discussion were Arendt's Eichmann in Jerusalem: A Report on the Banality of Evil and Thinking and Moral Considerations: A Lecture. In addition, a literature search was conducted through the employment of four electronic databases: Cumulative Index to Nursing and Allied Health Literature (CINAHL), PsycINFO, PubMed and Medline. The keywords searched included Arendt, care, compassion, ethics, judgement, Socrates and thinking. The search was limited to articles published in English between 2004-2014 to not only obtain recent scholarly research on the work of Arendt but also to capture the recent critical commentary surrounding widespread failings in nursing care.

\section{Discussion}

\section{Thoughtlessness, instrumental rationality and poor nursing care}

By reflecting upon the trial of Adolf Eichmann to consider how it was that so many so-called 'ordinary' German citizens could have participated or been implicated in the morally reprehensible activities that occurred during the Nazi regime, Arendt (1992) 
famously proposed that 'evil' could take a distinctively 'banal' form (p. 252). In speaking of 'the banality of evil', however, she is clear that she was in no way seeking to trivialize what was ‘the greatest catastrophe’ of the twentieth century (Arendt 2007, p. 487). Rather, Arendt was proposing that the possession of a 'wicked nature' was not a necessary condition for participating in acts that are often referred to as evil or wicked, and neither could the participation of so many people in those acts be coherently explained by suggesting that each individual was 'afflicted' with an inherently evil or wicked nature (Schiff 2012, p. 101). As she makes clear:

Some years ago, reporting the trial of Eichmann in Jerusalem, I spoke of 'the banality of evil' and meant with this no theory or doctrine but something quite factual, the phenomenon of evil deeds, committed on a gigantic scale, which could not be traced to any particularity of wickedness, pathology, or ideological conviction in the doer...However monstrous the deeds were, the doer was neither monstrous nor demonic...' (Arendt 1971, p. 417)

While noting the temptation to provide explanations that distance the perpetrators of morally reprehensible activities from ourselves, explanations that suggest that those individuals have deficient characters that are lacking in compassion and essentially different from our own, Arendt (1971) is clear that the participation in such activities is the ever present possibility of everybody. Indeed, noting what she perceived as Eichmann's mundane, prosaic character and his banal explanations for participating in the Nazi atrocities, Arendt (1971) concluded that rather than possessing a diabolically evil nature - however politically expedient the attribution of inherent evilness would have been (Benhabib 2000, p. 67) - Eichmann displayed 'a curious, quite authentic 
inability to think' (p. 417), and it is precisely this 'authentic inability to think' or 'thoughtlessness' that she posits as a more coherent and productive explanation of how it is that large numbers of people can carry out, contribute to or be complicit in morally reprehensible activities.

In order to begin to consider Arendt's reflections in relation to the widespread participation of nurses in poor care, however, it is first productive to situate this authentic inability to think or thoughtlessness within the context of that which can be understood as being intimately associated with thoughtlessness and which has variously been referred to as instrumental, technical or calculating rationality (see, e.g. Adorno \& Horkheimer 1997, Habermas 1970, Marcuse 2002, Schön 2013). Defined as the form of rationality that we employ when we calculate the most efficient and economical means to achieve a given end, instrumental rationality places increased emphasis on the possession of specialist knowledge and technical skills, along with the strict adherence to rules, procedures or protocols, in order to achieve, and continually maximize, that efficiency (Taylor 1991, pp. 4-6). Accordingly, this instrumental, technical and characteristically rule-governed form of rationality is to be understood as that which has gained increasing prevalence in modern health care organisations and which has come to govern the everyday clinical activities of modern nurses, as well as being the form of rationality - with its emphasis on the possession of specialist knowledge, technical skills and the adherence to rules, policies and procedures - that has gained precedence in nursing education and increasingly governs the character of the education that nursing students receive. The everyday clinical activities of nurses, for example, can be understood as being governed by instrumental rationality to the extent that many of those activities - such as the assessment of health care needs, the planning and implementation of nursing 
interventions and the recording and evaluation of the effectiveness of those interventions - all require those practitioners to possess a body of specialist knowledge, to be competent in the exercise of a variety of technical skills and - in a safe, effective and increasingly efficient manner - to exercise those skills in accordance with specific sets of rules, procedures and protocols.

In elucidating the association between instrumental rationality and that which Arendt refers to as thoughtlessness, it is important to note that because instrumental rationality is primarily concerned with achieving the most efficient means to a given end then it diminishes the importance of that which Arendt (1971) refers to as thinking, where thinking designates the reflective employment of reason to critically examine 'whatever comes to pass' (p. 418). However, the suggestion that instrumental rationality diminishes the importance of thinking - and, somewhat more provocatively, that the increasing prevalence of this rule-governed rationality in modern health care organisations entails a lack of thinking on the part of professional nurses - ought not to be understood as proposing that practitioners do not possess significant and sophisticated cognitive capacities as they carry out a vast array of clinical activities in a safe, effective and efficient manner. Rather, Arendt's work entails that in order for nurses to engage in those clinical activities, in order for nurses to exercise their skills in accordance with specific sets of rules, procedures and protocols in an increasingly effective and efficient manner, then it becomes necessary to limit the extent to which they engage in that reflective, critical rationality which Arendt refers to as thinking. However, the suggestion that instrumental, rule-governed rationality is intimately associated with thoughtlessness ought not to be understood as a devaluation of the role of instrumental rationality in modern health care. Indeed, it is difficult to see how nurses could effectively and efficiently engage in the vast array of clinical activities 
that are expected of them if they were engaged in a continual critical consideration of whatever came to pass; as Arendt (1971) makes clear: 'If we were responsive to this claim all the time, we would soon be exhausted' (p. 418).

While being integral to the efficient functioning of modern health care organisations, however, there are significant dangers inherent in the manner in which instrumental rationality diminishes the importance of individual engagement in thinking. In particular, Arendt’s work suggests that when instrumental, rule-governed rationality comes to gain increasing precedence in a culture, organisation or even society, and when the individual members that make up that culture, organisation or society are engaged in activities that require them to continually adhere to specific sets of rules, procedures and protocols to ensure the most efficient means to a given end, then there is a propensity for individuals to get 'habituated' to rule-governed rationality and the lack of thinking or thoughtlessness that ensures its efficient functioning. In particular, she proposes that:

By shielding people against the dangers of examination, it [thoughtlessness] teaches them to hold fast to whatever the prescribed rules of conduct may be at a given time...What people then get used to is not so much the content of the rules, a close examination of which would always lead them into perplexity, as the possession of rules under which to subsume particulars. In other words, they get used to never making up their minds (Arendt 1971, pp. 435-436).

The risks inherent in the widespread habituation of individuals to instrumental rationality and the thoughtlessness it necessitates, however, are made manifest when an organisation's rules change or become distorted in morally problematic ways (as 
can occur, for example, in the continual pursuit of forever renewed efficiency that characterises instrumental rationality). When such changes occur, Arendt's work suggests there is a danger that there will be widespread, thoughtless adherence to those morally problematic changes. For example, highlighting a number of historical instances when there has been moral reversals in a regime's codes and virtues, and the manner in which those reversals were adopted in a largely unreflective and thoughtless manner, Arendt (1971) proposes that 'the ease with which such reversals can take place under certain circumstances suggests indeed that everybody is asleep when they occur' (p. 436).

In seeking to provide a critical analysis of the occurrence of widespread participation in poor nursing care, such as that typified by the events at Mid Staffordshire, Arendt's work can therefore be understood as presenting a profound and controversial challenge to those traditional, established explanations that are commonly employed to account for the widespread participation of individuals in morally reprehensible activities (Swift, 2009, pp. 98-100). Her work opposes explanations that attempt to characterise the individuals who engage in such activities as people possessing natures or characters that are distant from our own; in particular, she challenges all explanations that invoke essentialist notions and attribute 'monstrous, corrupt natures' or 'pathological, deficient characters' to those individuals who display morally reprehensible behaviour. This is not to exclude the possibility that there may be individual nurses who deliberately engage in morally reprehensible activities, and who might justifiably be referred to as malicious, pernicious or even wicked. However, Arendt's work suggests that the widespread participation of individuals in such activities, such as the manner in which large numbers of nurses participated or were complicit in the care failings that occurred at 
Mid Staffordshire, cannot coherently be accounted for by proposing that each of those individuals possessed natures that were inherently lacking in compassion and that, as a consequence of chance, there occurred a collection of such deficient individual natures at that particular place and moment in time. Rather, Arendt's suggestion that such widespread participation in moral reprehensible activities is to be understood as a consequence of an habituation to rule-governed rationality and the thoughtlessness that ensures its efficient functioning brings those activities closer to our everyday lives and, in so doing, can be understood as a provocation for all nurses to gain an awareness of, guard against and take responsibility for the possibility of such thoughtlessness in their own practice.

\section{Socrates, nursing education and the prevention of future health care failings}

In order to stimulate an awareness of the thoughtlessness to which individuals can become habituated - and thereby engender the possibility of actively disrupting the widespread participation in poor nursing care - Arendt posits the need for the increased and active engagement of that critical, reflective rationality that she refers to as thinking. For example, she proposes that: 'When everybody is swept away unthinkingly by what everybody else does and believes in, those who think are drawn out of hiding because their refusal to join is conspicuous and thereby becomes a kind of action' (Arendt 1971, pp. 445-446). In seeking to elucidate this thinking that becomes 'a kind of action', and that may disrupt the widespread, habituated and thoughtless participation in morally reprehensible activities, Arendt presents a characterisation of the ancient Greek philosopher Socrates as an exemplary instance of this critical, reflective rationality or thinking. In doing so, she notes that the characteristic, interrogative approach that Socrates employed involved calling into 
question those seemingly simple words or concepts that are part of our everyday speech, words such as 'happiness, courage, justice, etc.' and which become mobile and elusive when we try and define them (Arendt 1971, p. 429). In particular, Socrates was concerned with questioning those who had a high reputation for wisdom, such as the professional men and politicians of Athens, to see if they could provide a coherent account of what they meant when they employed those everyday terms and thereby examine if their reputation for wisdom was warranted (e.g. Colaiaco 2001, Johnson 2012, Miller 2012). Socrates suggests, however, that he not only discovered that the high reputation of the professional men and politicians of Athens was unwarranted, not only were they unable to provide coherent accounts of what they meant when they employed those everyday terms, but their lack of wisdom was compounded in so far as they believed they possessed a level of wisdom that they manifestly did not (Plato 1961a, pp. 7-8).

In beginning to consider the implications of Arendt's employment of Socrates for nursing generally, and the providers of nursing education in particular, it is important to note that the value of Socrates' thinking for Arendt does not depend on the specific content of that thinking which Plato's dialogues recount. Indeed, Arendt (1971) makes it clear that 'Socrates, as he repeatedly said, did not teach anything for the simple reason that he had nothing to teach' (pp. 431-432). Despite suggesting that Socrates 'had nothing to teach' and that his philosophical activity can be understood as 'aporetic', Arendt (1971) is clear that the thinking he exemplified continues to possess a contemporary significance, value and worth (pp. 445-446). However, rather than evaluating that worth in terms of the specific content of Socrates' thought or the particular interrogative method that he employed, the value of Socrates for Arendt is to be understood as residing in the particular ethos, disposition or intellectual 
propensity that he embodies. While an individual's ethos, understood in its ancient Greek sense, is manifest in the way that a person acts and responds to events, it is not to be understood as being reducible to that way of acting or responding to events. Instead, an individual's ethos refers to their character and disposition towards things, an attitudinal or intellectual stance towards the world and which has been referred to as a person's mode or way of being (Foucault 2000, p. 286). The value of Socrates as an exemplary instance of that which Arendt refers to as thinking can therefore be understood as residing in the particular ethos that he embodies, in his possession of an attitude, way of being or propensity to question the seemingly self-evident 'truths' of everyday life, to call into question that which is regarded as 'common sense' and which 'everybody is supposed to know' (Bernstein 2000). It is this Socratic disposition or questioning propensity that maintains a contemporary significance for Arendt precisely because it has the ability to disrupt the habituated thoughtlessness that can be associated with the instrumental, rule-governed rationality that increasingly directs the everyday conduct of individuals within modern organisation and regimes (Arendt 1971 p. 434).

In considering the implications of Arendt's characterisation of Socrates for the providers of nursing education, therefore, it is important to note that her work entails the need to assist nursing students to develop a Socratic ethos, disposition or questioning propensity rather than learning, and attempting to duplicate, the particular technical, interrogative method that he employed. Indeed, the teaching and acquisition of that method, or even more general skills of critical thought and reflection, will be of limited value in seeking to challenge the thoughtless widespread participation of nurses in health care failings if those practitioners lack the particular ethos that disposes them to employ those skills and question the established and seemingly 
unquestionable rules, procedures and protocols of the organisation within which they work. Rather, it is the development of a disposition or propensity to question that may challenge the thoughtlessness that can lead to the widespread participation of nurses in poor care, a Socratic ethos that arises from an active suspicion towards all claims of what can be referred to as epistemological certitude, finality or closure, a suspicion towards any individual, professional body or organisation that effectively maintains that its knowledge base, procedures or protocols are, in theory or in practice, beyond question. Indeed, congruent with much contemporary thought in the spheres of religion, politics, philosophy and science (e.g. Lyotard 1997, Vattimo 1999, Rorty 2007, Kuhn 2012), Arendt (1971) proposes that the long-standing intellectual pursuit of attempting to establish epistemological certitude, the multiple claims to have discerned or uncovered truths that are effectively indubitable, has 'lost plausibility', 'fallen into disrepute' and ‘come to an end' (pp. 419-421). The particular disposition that Arendt suggests Socrates exemplifies is, in this respect, strikingly contemporary in so far as he maintained that he knew nothing of such epistemological certitude and that indubitable, unquestionable knowledge claims would have to be the reserve of a God, whereas the knowledge that human beings could possess would always be provisional, subject to revision and forever open to question (Plato 1961a, p. 9).

In order to disrupt the manner in which nurses may become progressively habituated to the thoughtlessness that is associated with instrumental, rule-governed rationality - habituated to the widespread participation in the most efficient means to a given end without considered reflection on the moral appropriateness of the means employed or the ends pursued - Arendt's work entails that it is necessary to facilitate the development of a Socratic ethos in nursing students. However, in contrast to the teaching of technical skills and the assessment of their safe, effective and efficient 
performance, the facilitation of a disposition that reflects an active suspicion towards claims of epistemological certitude, an ethos that disposes nursing students to question that which is supposedly unquestionable, presents a significant challenge to the providers of nursing education. Indeed, in highlighting this difficulty, Arendt (1971) suggests that there is only one way that such a Socratic ethos can be taught, the only way in which she suggests that Socrates can be understood as having taught anything, and that is by presenting, sharing and discussing 'perplexities' with others (p. 431). That is, in order to facilitate the development of a disposition or propensity to question, and thereby develop that thinking which may disrupt the widespread thoughtless participation of nurses in future health care failings, then it is necessary to present critical debates and issues to nursing students, to investigate and discuss the uncertainties, controversies and perplexities that surround the theoretical foundations and clinical interventions that characterize contemporary health care. However, as Socrates made clear (Plato 1961b, p. 363), the discussion of those perplexities does not entail an investigation in which 'the educator', from an ostensible position of expertise and certitude, seeks to conclude or terminate the investigation by revealing the supposed answer or solution that somehow resolves the perplexity. Rather, in accordance with the description of Socrates as a perplexed man who reduced others to perplexity (Plato 1961b, p. 363), the development of a questioning disposition is made by an educator who is genuinely disposed to conduct a mutual investigation into the uncertainties, controversies and perplexities that characterise contemporary health care, valuing the contribution of nursing students as co-inquisitors and, in doing so, creating a climate in which those students feel empowered, validated and disposed to engage in critical, reflective questioning (Roberts 2014). 
While facilitating the development of such a Socratic ethos involves creating a climate in which nursing students feel empowered and disposed to question, those responsible for the education of nurses also face the challenge of considering how to encourage students to exercise that disposition, and consider the consequences of exercising that disposition, in environments that are less receptive to such questioning. Indeed, Socrates' account at his trial of the manner in which his propensity to ask questions evoked bitter and persistent hostility from most of the individuals that were subject to that questioning, along with the judgment passed on him at the end of that trial by the professional men and politicians of Athens, vividly illustrates how individuals, organisations and regimes can react to the reflective, questioning disposition that he exemplified (Plato 1961a, p. 9, p. 23). Similarly, Arendt (1971) notes the manner in which the Athenians accused Socrates of being dangerously subversive and corrosive, and that the questioning disposition he exercised 'sweeps away all the established signs by which men orient themselves in the world; it brings disorder into the cities and it confuses the citizens, especially the young ones' (p. 436). To the extent that an individual, professional body or organisation has an interest in maintaining its authority and reputation for knowledge, and within the context of the increasing prevalence of instrumental, rule-governed rationality in modern health care organisations, then the questioning disposition that Socrates exemplified may be regarded as an annoyance at best and, at worst, a subversive challenge to the legitimacy and the efficient functioning of the organisation. To facilitate the acquisition of a Socratic questioning propensity in nursing students, therefore, does not merely necessitate the development of an attitude of suspicion to claims of epistemological certitude, but also the development of the courage to actively engage that suspicion and ask questions of individuals, professional bodies and organisations 
who may have a multiplicity of historical, socio-political and institutional reasons to maintain the seemingly self-evident and unquestionable status of their knowledge base, procedures and protocols.

\section{Implications for Nursing}

Despite the challenges confronting nursing educationalists who would seek to facilitate the development of a Socratic ethos in student nurses, Arendt's work is clear that such a disposition can serve as a corrective to the authentic inability to think or thoughtlessness that can be associated with the instrumental, rule-governed rationality that increasingly characterises modern health care organisations. However, in contrast to the possession of specialised, technical nursing skills and the increasingly efficient employment of those skills in accordance with organisational rules, policies and produces, the development of that reflective, questioning disposition towards supposedly self-evident truths that Arendt refers to simply as thinking is to be understood as a general attribute of all. As she makes clear: 'Thinking in its noncognitive, non-specialized sense...is not a prerogative of the few but an everpresent faculty of everybody’ (Arendt 1971, p. 445). While modern health care organisations require nurses, as an integral part of those organisations, to possess and exercise technical skills in order to ensure the most effective and efficient means to a given end, the prevention of widespread thoughtless participation in health care failings also requires them to possess an ethos that disposes them, when necessary and in the face of individual, professional and organisational resistance, to actively question the moral appropriateness of the means being employed or the ends being pursued. As an ever present faculty of all nurses, Arendt's work suggests that the providers of nursing education seriously consider how to facilitate the development and active engagement 
of a Socratic ethos in student nurses, how this can be set alongside the educational demands of facilitating the acquisition of specialised knowledge and technical health care skills and, finally, how the two can coexist in modern health care organisations that are increasingly characterised by instrumental, rule-governed rationality.

\section{Conclusion}

In seeking to provide a detailed critical analysis of the occurrence of widespread participation of nurses in poor care, such as that typified by the events at Mid Staffordshire, this paper has sought to employ and re-contextualise the challenging work of Hannah Arendt. In doing so, it has suggested that from an Arendtian perspective the occurrence of widespread failings in nursing care cannot coherently be accounted for by attributing wicked natures, pathological temperaments or deficient characters to individual practitioners, but should rather be understood as a consequence of an habituation to the thoughtlessness that can be intimately associated with the instrumental, rule-governed rationality that has increasingly come to characterise modern health care organisations. Moreover, Arendt's employment of Socrates as an exemplary instance of that thinking that may disrupt the widespread thoughtless participation in morally reprehensible activities presents the providers of nursing education with both opportunities and challenges for how to facilitate an ethos or disposition which may limit the widespread participation of nurses in future health care failings. In particular, the contemporary significance of the Socratic questioning disposition, that propensity to ask questions when it appears that there are no more questions left to ask, lies precisely in its ability to disrupt the habituated thoughtlessness that is characteristic of instrumental rationality and the pursuance of the most efficient means to a given end. It is precisely when morally questionable 
reversals in an organisation begin to take place that this Socratic disposition manifests its full potential because it is at such moments that those nurses who have the courage to ask seemingly unproductive and inefficient questions in the face of the predominant demand to maximise efficiency, will open a space of possibility for disrupting the widespread, habituated and thoughtless participation in future health care failings. 


\section{References}

Abassi K. (2013) What is candour without accountability? Journal of the Royal Society of Medicine 106, 75.

Adorno T.W. \& Horkheimer M. (1997) Dialectic of Enlightenment. Verso, London.

Arendt H. (1971) Thinking and moral considerations: a lecture. Social Research 38, 417-446.

Arendt H. (1981) The Life of the Mind. Harcourt, San Diego, CA.

Arendt H. (1985) The Origins of Totalitarianism. Harcourt, San Diego, CA.

Arendt H. (1990) On Revolution. Penguin, Harmondsworth.

Arendt H. (1992) Eichmann in Jerusalem: A Report on the Banality of Evil. Penguin, New York.

Arendt H. (1998) The Human Condition. University of Chicago Press, Chicago.

Arendt H. (2007) The Jewish Writings. Schocken Books, New York.

Benhabib S. (2000) Arendt's Eichmann in Jerusalem. In The Cambridge Companion to Hannah Arendt (Villa D. ed), Cambridge University Press, Cambridge, pp. 65-85. 
Bernstein R.J. (2000) Arendt on Thinking. In The Cambridge Companion to Hannah Arendt (Villa D. ed), Cambridge University Press, Cambridge, pp. 277-292.

Bowring F. (2011) Hannah Arendt: A Critical Introduction. Pluto Press, London.

Colaiaco J.A. (2001) Socrates Against Athens: Philosophy on Trial. Routledge, New York.

Darbyshire P. \& McKenna L. (2013) Nursing’s crisis of care: what part does nursing education own? Nurse Education Today 33, 305-307.

Dewar B. \& Nolan M. (2013) Caring about caring: developing a model to implement compassionate relationship centred care in an older people care setting. International Journal of Nursing Studies 50(9), 1247-1258.

Dewar B., Adamson E., Smith S., Surfleet J. \& King L. (2014) Clarifying misconceptions about compassionate care. Journal of Advanced Nursing 70(8), 1738-1747.

De Zulueta, P. (2013) Reflecting on the Francis Report: How we can develop more human systems of care. Nursing Ethics 20(7), 838-839.

Foucault M. (2000) The ethics of the concern of the self as a practice of freedom. In Ethics: Subjectivity and Truth (Rabinow P. ed), Penguin, London, pp. 281-301. 
Francis R. (2013) Report of the Mid Staffordshire NHS Foundation Trust Public Inquiry. The Stationary Office, London.

Garner J. (2014) Some thoughts and responses to The Francis Report. Psychoanalytic Psychotherapy 28(2), 211-219.

Habermas J. (1970) Towards A Rational Society: Student Protest, Science and Politics. Beacon Press, Toronto.

Hayter M. (2013) The UK Francis Report: the key messages for nursing. Journal of Advanced Nursing, 69(8), e1-e3.

Health Service Ombudsman (2011) Care and compassion: Report of the Health Service Ombudsman on ten investigations into NHS care of older people. The Stationary Office, London.

Holmes D. (2013) Mid Staffordshire scandal highlights NHS cultural crisis. The Lancet 381, 521-522.

Horsburgh D. \& Ross J. (2013) Care and compassion: the experiences of newly qualified staff nurses. Journal of Clinical Nursing 22, 1124-1132.

Johnson P. (2012) Socrates: A Man for our Times. Penguin, London. 
Kapur N. (2014) Mid Staffordshire Hospital and the Francis Report. The Psychologist 27(1), 16-20.

Kuhn T.S. (2012) The Structure of Scientific Revolutions. The University of Chigaco Press, Chicago.

Lyotard, J.F., 1997. The Postmodern Condition: A Report on Knowledge. Manchester University Press, Manchester.

Marcuse H. (2002) One-Dimensional Man: Studies in the Ideology of Advanced Industrial Society. Routledge, London.

Miller J. (2012) The Philosophical Life. Oneworld Publications, Oxford.

Paley J. (2013) Social psychology and the compassion deficit. Nurse Education Today 33, 1451-1452.

Patients Association (2011) We've been listening, have you been learning? Patient's Association, London.

Plato (1961a) The Apology. In The Collected Dialogues of Plato (Hamilton E. \& Cairns H. eds), Princeton University Press, Princeton, pp. 3-26.

Plato (1961b) The Meno. In The Collected Dialogues of Plato (Hamilton E. \& Cairns H. eds), Princeton University Press, Princeton, pp. 353-384. 
Roberts M. (2014) Beyond the bounds of the dogmatic image of thought: The development of critical, creative thinking in the mental health professions. Journal of Psychiatric and Mental Health Nursing 21, 313-319.

Rorty R. (2007) Contingency, Irony, and Solidarity. Cambridge University Press, Cambridge.

Schiff J. (2012) The varieties of thoughtlessness and the limits of thinking. European Journal of Political Theory 12, 99-115.

Schön D. (2013) The Reflective Practitioner: How Professionals Think in Action. Ashgate Publishing, London.

Swift S. (2009) Hannah Arendt. Routledge, Abingdon.

Taylor C. (1991) The Ethics of Authenticity. Harvard University Press, Cambridge, Mass.

Tingle J. (2014) The Francis report: one year on. British Journal of Nursing 23(5), 284-285.

Vattimo G. (1999) Belief. Blackwell, Oxford. 